Published in final edited form as:

Int J Cancer. 2007 July 15; 121(2): 339-346. doi:10.1002/ijc.22635.

\title{
Pesticide use and colorectal cancer risk in the Agricultural Health Study
}

Won Jin Lee ${ }^{1}$, Dale P. Sandler ${ }^{2}$, Aaron Blair ${ }^{3}$, Claudine Samanic $^{3}$, Amanda J. Cross ${ }^{3}$, and Michael C. R. Alavanja ${ }^{3,{ }^{*}}$

${ }^{1}$ Department of Preventive Medicine, College of Medicine, Korea University, Seoul, Korea

${ }^{2}$ Epidemiology Branch, National Institute for Environmental Health Sciences, Research Triangle Park, North Carolina, USA

${ }^{3}$ Division of Cancer Epidemiology and Genetics, National Cancer Institute, National Institutes of Health, Rockville, Maryland, USA

\begin{abstract}
We investigated the relationship between agricultural pesticides and colorectal cancer incidence in the Agricultural Health Study. A total of 56,813 pesticide applicators with no prior history of colorectal cancer were included in this analysis. Detailed pesticide exposure and other information were obtained from self-administered questionnaires completed at the time of enrollment (1993-1997). Cancer incidence was determined through population-based cancer registries from enrollment through December 31, 2002. A total of 305 incident colorectal cancers (212 colon, 93 rectum) were diagnosed during the study period, 1993-2002. Although most of the 50 pesticides studied were not associated with colorectal cancer risk, chlorpyrifos use showed significant exposure response trend ( $p$ for trend $=0.008$ ) for rectal cancer, rising to a 2.7 -fold (95\% confidence interval: 1.2-6.4) increased risk in the highest exposure category. Aldicarb was associated with a significantly increased risk of colon cancer ( $p$ for trend $=0.001$ ), based on a small number of exposed cases, with the highest exposure category resulting in a 4.1 -fold increased risk $(95 \%$ confidence interval: 1.3-12.8). In contrast dichlorophenoxyacetic acid showed a significant inverse association with colon cancer but the association was not monotonic. Our findings should be interpreted cautiously since the literature suggesting that pesticides are related to colorectal cancer is limited. Nonetheless the possibility of an association between exposure to certain pesticides and incidence of colorectal cancer among pesticide applicators deserves further evaluation.
\end{abstract}

\section{Keywords}

agriculture; colorectal cancer; farmers; insecticides; occupational exposure; pesticides

\section{Introduction}

Colorectal cancer is the third most common incident cancer in the United States, with an estimated 106,370 new diagnoses of colon cancer and 40,570 rectal cancers in the year 2004 in the United States. ${ }^{1}$ The substantial worldwide variation in incidence rates for colorectal cancer may be explained by dietary and other environmental factors. ${ }^{2}$ Colorectal cancer is not commonly considered to be occupational in etiology, but elevated risks have been reported

\footnotetext{
"Correspondence to: Michael C.R. Alavanja, DrPH., 6120 Executive Blvd. EPS 8000, Occupational and Environmental Epidemiology Branch, Division of Cancer Epidemiology and Genetics, National Cancer Institute, Rockville, Maryland, 20852, USA, alavanjm@mail.nih.gov, Phone: 301435 4720; Fax: 3014021819.
} 
among workers in the textile industry, ${ }^{3,4}$ in the automobile industry, ${ }^{5-7}$ in the beverage industry, ${ }^{8}$ in subjects exposed to asbestos, ${ }^{9-12}$ dioxin,,${ }^{13}$ wood dust, ${ }^{14}$ organic solvents ${ }^{15-17}$ and metal-working fluids. ${ }^{18}$

The risk of colorectal cancer is generally found to be lower in farmers, although the reason for these deficits are not entirely clear, lower smoking rates and higher levels of physical activity may be involved. ${ }^{19}$ Some epidemiologic studies have found a link between exposure to pesticides and risk of colorectal cancer. In mortality studies from Italy ${ }^{20}$ and Iceland ${ }^{21}$, risks of rectal cancer were increased in farmers. In a study of pesticide manufacturing workers from the Netherlands ${ }^{22}$ and a follow-up study in the same population, ${ }^{23}$ the risk of rectal cancer was about three-fold among those exposed to the insecticides dieldrin and aldrin. An excess risk of mortality from rectal cancer was observed in a cohort of workers from organochlorine pesticide manufacturing plants in the United States. ${ }^{24}$ Elevated colorectal cancer risks have been observed in American cohorts of manufacturing workers exposed to the herbicide alachlor. 25-27 A study from Egypt reported that colorectal cancer patients had higher serum organochlorines levels than controls. ${ }^{28}$ Other studies of farmers ${ }^{29,30}$ and pesticide manufacturers, ${ }^{31-33}$ however, did not show any excess risk of colorectal cancer.

Previous studies have had limited information on pesticide exposure, small sample size, and inadequate control of potential confounders, such as certain dietary factors. To more carefully evaluate whether agricultural pesticide exposures were associated with the risk of colorectal cancer in a farming population, we examined risks among participants in the Agricultural Health Study cohort.

\section{Material and methods}

\section{Study population}

The Agricultural Health Study is a prospective cohort of certified pesticide applicators and their spouses in Iowa and North Carolina. ${ }^{34}$ Recruitment began in December 1993 and continued through December 1997. A total of 57,311 private and commercial pesticide applicators (approximately $84 \%$ of eligible applicators in both States) enrolled in the study by completing an enrollment questionnaire when they sought a restricted-use pesticide license from the State Cooperative Extension Services or Department of Agriculture. Private applicators were farmers or nursery workers, and commercial applicators were persons employed by pest control companies or businesses that use pesticides. In Iowa, both commercial and private applicators attend the same pesticide certification testing sessions, and both were invited to participate in the study. In North Carolina, because private applicators attended separate training, only private applicators were enrolled. Private and commercial applicators were also asked to complete "take-home" questionnaires that sought more extensive information on physical activity, dietary habits and medical conditions as well as exposure details for some of the pesticides of interest. The take-home questionnaire was completed by 25,291 applicators (44\%).

Of the 57,311 total pesticide applicators in the Agricultural Health Study cohort, those with a diagnosis of colorectal cancer prior to enrollment $(n=159)$ or those who were not residents of Iowa or North Carolina at the time of licensing $(\mathrm{n}=339)$ were excluded from the present study, leaving 56,813 eligible applicators.

\section{Case ascertainment}

Cohort members are matched to cancer registry files in Iowa and North Carolina annually for case identification and to the state death registries and to the National Death Index annually to ascertain vital status. For the current analysis, incident cancers were identified from the date 
of enrollment (i.e., 1993-1997) through December 31, 2002. Colorectal cancers were coded according to the International Classification of Diseases for Oncology (ICD-O-2). ${ }^{35}$ Cohort members who were alive at the end of follow-up, but no longer residing in Iowa or North Carolina $(n=658)$, were identified through the current address records of the Internal Revenue Service, motor vehicle registration offices, and pesticide license registries of State agriculture departments. Person-year accumulation was censored for these individuals in the year that they left Iowa or North Carolina. All participants provided verbal informed consent, and institutional review boards of the National Cancer Institute, Batelle (the field station in North Carolina), the University of Iowa (the field station in Iowa), and Westat (coordinating center for the study) approved the protocol.

\section{Exposure assessment}

The self-administered enrollment questionnaire collected comprehensive exposure data on 22 pesticides and ever/never use information on 28 additional pesticides, as well as information on use of personal protective equipment, pesticide application methods, pesticide mixing status, equipment repair status, smoking history, alcohol consumption, fruit and vegetable intake, medical conditions, history of colorectal cancer in first-degree relatives and basic demographic data. All participants who completed the enrollment questionnaire were also given a self-administered take-home questionnaire that included more detailed information on the 28 pesticides reported as ever/never use in the enrollment questionnaire and additional information on lifestyle characteristics, height and weight, dietary habits, hours spent in strenuous physical activity, medical history and use of aspirin and other medications. Both questionnaires may be found at http://www.aghealth.org/questionnaires.html.

Data from the enrollment questionnaire and measurement data from the published pesticide exposure literature were used to estimate the intensity of exposure to individual pesticides using the following formula: intensity level $=$ (mixing status + application method + equipment repair status) $\times$ personal protective equipment use, where the various levels of the four elements of the intensity score were weighted to reflect their importance on exposure. ${ }^{36}$

We constructed two lifetime pesticide exposure variables for this analysis. The first, lifetime exposure-days, was based on the number of years an applicator personally applied or mixed specific pesticide multiplied by the mean number of days in an average year an applicator personally mixed or applied each pesticide (i.e., years of use $x$ days per year). The second lifetime pesticide exposure variable, intensity-weighted exposure-days, was lifetime exposuredays multiplied by the intensity level (i.e., years of use $\times$ days per year $\times$ intensity level). Both exposure variables were available for all applicators on 22 pesticides included in the enrollment questionnaire, but they were only available for the subset of applicators that returned the takehome questionnaire on the remaining 28 pesticides.

\section{Data analysis}

We conducted unconditional multivariate logistic regression ${ }^{37}$ to compare colorectal cancer cases with non-cases on a number of factors possibly associated with colorectal cancer risk since the follow-up period for case ascertainment was relatively short and the colorectal cancer incidence rate did not vary appreciably during the period. We estimated the odds ratios (ORs) and 95 percent confidence interval (CI) for colorectal cancer for individual pesticides. The reference groups for the various analyses are indicated in the tables. For the pesticide analyses, the referents included all applicators who did not mix or apply the specific pesticide. Applicators were classified as exposed or not to specific pesticides, and among those who reported using the pesticide, the exposures were classified in tertiles based on the distribution of exposure days or intensity weighted pesticide days reported by cases. If the highest tertile 
contained 10 or more exposed cases, it was further divided into two for the exposure response analysis.

All ORs were adjusted for age ( $<45,45-49,50-54,55-59,60-64,65-69,70-74$ and $\geq 75$ years), state of residence (Iowa, North Carolina), smoking history (never, $<11,11-27,>27$ pack-years) and by total pesticide application days to any pesticide $(<87.5,87.5-224.7,224.8-507.5,>507.5$ days). The total days of pesticide application was used as a surrogate measure of other potential pesticide and farming exposure. The tertile value of pack-years and quartiles of total pesticide application days among colorectal cancer cases were used to classify the categories. To control more fully for potential confounders, we also included variables for body mass index, race, license type, education level, aspirin intake, family history of colorectal cancer, physical activity, smoking, as well as intakes of meat, fruits, vegetables and alcohol. Since the ORs for colorectal cancer did not vary meaningfully for any pesticide examined in the two models, the smaller models are presented.

We analyzed exposure-response trends by including the categorical score (i.e., $0,1,2,3$ ) of each group as a continuous variable in the models and testing for the statistical significance of the slope. All tests of statistical significance were two-sided $(\alpha=0.05)$. In addition, we conducted sub-analyses of colorectal cancer risk by state, as well as anatomic sub-sites separately (i.e., proximal colon including cecum, appendix, and ascending colon; transverse colon including hepatic flexure, transverse colon, and splenic flexure; distal colon including descending and sigmoid colon; rectosigmoid junction; and rectum).

\section{Results}

A total of 305 incident colorectal cancers occurred among applicators during the mean followup period of 7.3 years between enrollment (i.e., 1993-1997) and December 31, 2002. Odds ratios for colorectal cancer from various factors are shown in Table 1. Age and smoking were significant risk factors for colorectal cancer in the pesticide applicators in the Agricultural Health Study. Elevated colorectal cancer risk was also observed among those in the highest quartile ( $\geq 30.5$ ) of body mass index. Elevated, but non-significant, excess colorectal cancer risks were observed among non-Caucasian compared with Caucasian applicators and among commercial applicators compared with private applicators. A non-significant inverse association was observed with educational level, recreational physical activity and vegetable intake. No differences were found by state of residence, gender, marital status, or return of the take-home questionnaire. The characteristics of farmers who completed only the enrollment questionnaire were quite similar to those of farmers who also completed and returned the takehome questionnaire. ${ }^{38}$ Family history of colorectal cancer among first-degree relatives, use of aspirin, alcohol intake and dietary factors such as fruit, vegetable or meat consumption were not associated with colorectal cancer risk.

The ORs for ever-use of specific pesticides are presented in Table 2. Among 50 commonly used pesticides, two insecticides (aldicarb and fonofos) were significantly associated with elevated risks of colorectal cancer $(\mathrm{OR}=1.6 ; 95 \% \mathrm{CI} 1.0-2.4$; $\mathrm{OR}=1.4 ; 95 \% \mathrm{CI} 1.0-1.9$, respectively), which was due primarily to the excess risks of colon cancer; whereas the herbicide 2,4-dichlorophenoxyacetic acid (2,4-D) was inversely associated with colorectal cancer risk $(\mathrm{OR}=0.7 ; 95 \% \mathrm{CI} 0.5-0.9)$. Two other insecticides (carbaryl and toxaphene) showed significant increased risks of rectal cancer $(\mathrm{OR}=2.0 ; 95 \% \mathrm{CI} 1.1-3.5 ; \mathrm{OR}=2.1 ; 95 \%$ CI 1.2-3.6, respectively). Results were similar for those who did and did not complete the takehome questionnaire (data not shown). None of the fungicides or fumigants was associated with colorectal cancer risk (Table 2). 
The exposure-response relationships with lifetime exposure days for colorectal cancer and nine pesticides are shown in Table 3. The nine pesticides reflect those with either positive or negative associations in the ever-exposure analyses, some evidence of an exposure-response relation, or an a priori interest. A significant exposure-response trend was observed for rectal cancer ( $p$ trend $=0.008$ ) with the lifetime exposure-days of chlorpyrifos (a phosphorothioate insecticide) use, rising to a 2.7 -fold increased risk $(95 \% \mathrm{CI}=1.2-6.4)$ in the highest exposure category. Aldicarb (a carbamate insecticide) exhibited significant increasing trend for colon cancer with increasing lifetime days of use $(p$ trend $=0.001$ ), with the highest exposure category resulting in a 4.1-fold increased risk $(95 \% \mathrm{CI}=1.3-12.8)$. In contrast, $2,4-\mathrm{D}$ (a phenoxy herbicide) showed an inverse association with colon cancer $(p$ trend $=0.011)$. No other significant exposure-response trends were observed among the other individual pesticides evaluated in our analyses. The intensity-weighted exposure-days algorithm for these pesticides generally produced similar estimates for colorectal cancer risk compared to lifetime days of pesticide exposure and these results are not shown. Results from analyses stratified by state were similar (data not shown).

Because detailed exposure information for many of the pesticides was only available for the subset of participants who completed the take-home questionnaire, we also repeated the analyses for pesticides for which frequency data were available on the enrollment questionnaire, restricting the analysis to those who also completed the take-home questionnaire. Results were essentially unchanged (data not shown). Risks for colorectal cancer associated with specific pesticides did not vary with anatomical subtype, although our power to detect any differences was limited (data not shown).

\section{Discussion}

We found that a few pesticides, in particular chlorpyrifos and aldicarb, were associated with significant excess risks of rectal or colon cancer among pesticide applicators in the Agricultural Health Study cohort. Since we evaluated 50 pesticides and did not have strong a priori hypotheses linking specific pesticides with human colorectal cancer risk, these maybe chance findings from small numbers and multiple comparisons. However, these excesses did show consistency of the findings by state and some evidence of an exposure-response relation.

Chlorpyrifos [O,O-diethyl- $O$-(3,5,6-trichloro-2-pyridyl)-phosphorothioate] is one of the most widely used organophosphate insecticides in the United States. ${ }^{39}$ Although the literature provided little evidence of mutagenic or carcinogenic effects of chlorpyrifos in humans, 40 some experimental studies found that chlorpyrifos induced mutagenicity, 41,42 sisterchromatid exchanges ${ }^{43,44}$ and chromosomal loss. ${ }^{45}$ Chlorpyrifos has been found to modify endogenous antioxidants in rats, possibly leading to the development of oxidative stress. ${ }^{46} \mathrm{~A}$ case-control study reported increased risk of non-Hodgkin's lymphoma ${ }^{47}$ and glioma ${ }^{48}$ among male farmers exposed to chlorpyrifos in the United States. In a previous analysis of cancer among chlorpyrifos users in the Agricultural Health Study cohort, we reported an increased risk of rectal cancer consistent with our current findings, as well as excesses for cancers of the lung and brain. ${ }^{49,50}$ However, the biologic mechanisms for carcinogenicity of chlorpyrifos is not clear and should be further studied.

Aldicarb [2-methyl-2-(methylthio) propionaldehyde-O-methylcarbamoyloxime] is a carbamate insecticide. Since aldicarb has not been tested extensively for carcinogenicity in experimental animals and there are no adequate human studies of the relationship between exposure to aldicarb and human cancer reported to date,51 our positive association with colon cancer is new and unexpected. The only human study, which had an ecologic design, found that aldicarb application was associated with breast cancer incidence in England.53 However, our results were based on a small number of exposed cases $(n=29)$, so we will need to continue 
to follow-up before a firm conclusion about colon cancer and aldicarb exposure can be made. Another insecticide showed a positive association with colon cancer (fonofos) and two were positively associated with rectal cancer (carbaryl and toxaphene) by ever/never exposure history; however, they did not have significant exposure-response relationships, which weakens a causal inference.

We did not find significant associations with alachlor, aldrin, and dieldrin, which are all pesticides previously associated with colorectal cancer in production workers. ${ }^{22,23,25-27}$ However, these previous studies from pesticide manufacturing workers were based on few colorectal cancer cases. Our previous study from the Agricultural Health Study cohort ${ }^{53}$ also did not support any significant association between alachlor exposure and colorectal cancer risk.

Unexpectedly we found a lower risk of colon cancer among applicators ever exposed to 2,4D. Previous epidemiologic studies of 2,4-D have focused on risks for soft tissue sarcoma, nonHodgkin's lymphoma, and Hodgkin's disease, but on few other cancers. ${ }^{54}$ A slight excess of colon cancer among farmers in Kansas reporting use of 2,4-D was based on small numbers. 29 The lack of a monotonic exposure-response pattern with lifetime exposure-days weakens somewhat the argument for a true protective relationship, but further evaluation of this inverse association is planned for the Agricultural Health Study cohort.

No significant exposure-response relation between pendimethalin and rectal cancer was observed here, whereas a previous report on pendimethalin from the Agricultural Health Study found a significantly increased risk of rectal cancer among applicators with the highest lifetime pendimethalin exposure days. ${ }^{55}$ The difference in results is due to use of different exposure cut-points. In the chemical specific analysis, the tertiles were based on total number of cancer cases, but here the tertiles were based on specific pesticide use by colorectal cancer cases. The instability in the risk estimate for rectal cancer and pendimethalin exposure using different cut points suggests that the results should be interpreted cautiously.

We attempted to evaluate the relationship between pesticide exposure and risk of colorectal cancer by anatomic sub-sites because previous studies have suggested etiologic distinctions by anatomic sub-site. ${ }^{56,57}$ Occupational factors also have been reported to influence the risk of colon and rectal cancer in different ways ${ }^{58,59}$ However, the pesticides we analyzed did not show significantly different risks by anatomic sub-sites, although the number of cases in the sub-groups was small.

Other factors that may be related to colorectal cancer risk (i.e., physical activity, body mass index, and smoking) showed results consistent with previous literature ${ }^{2}$ while others (i.e., family history of colorectal cancer among first-degree relatives, dietary factors and use of aspirin) were not associated with colorectal cancer risk within the Agricultural Health Study cohort. Since these factors were not a focus of the Agricultural Health Study research, our data on dietary factors, non-steroidal anti-inflammatory drug use and family cancer history were limited and it is possible that misclassification of these exposures may have masked expected associations. The number of regular users of aspirin and other non-steroidal anti-inflammatory drugs was small, possibly reflecting the fact that applicators were relatively healthy at enrollment. Adjusting for lifestyle factors known to be related to colorectal cancer risk did not alter our results.

One possible limitation of this study is the potential recall bias associated with subjects recalling pesticide use from many years ago. We have carried out several efforts to assess the reliability of our pesticide data. A previous evaluation of this issue has shown that recall of pesticide use by the Agricultural Health Study cohort is as reliable as that for other factors routinely evaluated by questionnaire in epidemiology studies, such as smoking and alcohol 
use, and to be better than others, such as consumption of fruits and vegetables and physical activity. ${ }^{60}$ In addition, we have found that participants in our cohort have provided plausible information regarding the duration of use of specific pesticides. ${ }^{61} \mathrm{~A}$ recent report showed that our pesticide exposure scores provide a reasonably valid measure of exposure intensity for pesticide applicators by comparing pesticide exposure algorithm and urine metabolites monitoring results. ${ }^{62}$ Although these findings are encouraging, undoubtedly exposure misclassification occurs. This misclassification would be expected to be nondifferential for cases and non-cases and the observed effect estimates would likely be biased toward the null.

Since we examined risks for 50 pesticides, it is possible that as a result of multiple comparisons, some significant findings might have occurred by chance alone. The appropriate method for adjusting for multiple comparisons in epidemiologic studies, and even the need to do so, has been a matter of some controversy. ${ }^{63-65}$ However, consistency of the findings across states, replication of similar results among participants who completed the take-home questionnaire, and some evidence of an exposure-response relation in our study provide some protection against purely chance results.

Despite these limitations, the Agricultural Health Study has several important strengths over previous studies of pesticide use and cancer risk. This study is the largest epidemiologic study of applicators exposed to pesticides that has been conducted to date. All exposure information was collected prior to the diagnosis of cancer, which reduces concerns regarding bias due to differential reporting among cases and non-cases. This study included comprehensive questionnaire data that were used to quantitatively estimate pesticide exposure levels and to control for potential confounding from lifestyle factors. In addition, cancer incidence was obtained from population-based tumor registries, which eliminates issues related to survival when mortality data are the outcome. The follow-up of cohort members is also very high in this cohort (>99\%).

In conclusion, this explorative study suggests an association between the incidence of colorectal cancer and use of certain pesticides, in particularly chlorpyrifos and aldicarb, although some findings could be due to chance. Given the limited epidemiologic and laboratory research on these pesticides and on environmental causes of colorectal cancer, further research is warranted.

\section{Acknowledgments}

This research was supported (in part) by the Intramural Research Program of NIH (National Cancer Institute and National Institute of Environmental Health Sciences).

\section{References}

1. Jemal A, Tiwari RC, Murray, Ghafoor A, Samuels A, Ward E, Feuer EJ, Thun MJ. Cancer statistics, 2004. CA Cancer J Clin 2004;54:8-29. [PubMed: 14974761]

2. Potter JD. Colorectal cancer: molecules and populations. J Natl Cancer Inst 1999;91:916-32. [PubMed: 10359544]

3. Mastrangelo G, Fedeli U, Fadda E, Milan G, Lange JH. Epidemiologic evidence of cancer risk in textile industry workers: a review and update. Toxicol Ind Health 2002;18:171-81. [PubMed: 12974540]

4. Andersen A, Barlow L, Engeland A, Kjaerheim K, Lynge E, Pukkala E. Work-related cancer in the Nordic countries. Scand J Work Environ Health 1999;25 2:1-116. [PubMed: 10507118]

5. Swanson GM, Belle SH, Burrows RW Jr. Colon cancer incidence among modelmakers and patternmakers in the automobile manufacturing industry. A continuing dilemma. J Occup Med 1985;27:567-9. [PubMed: 3875701]

6. Hoar SK, Bang KM, Tillett S, Rodriguez M, Cantor KP, Blair A. Screening for colorectal cancer and polyps among pattern makers. J Occup Med 1986;28:704-8. [PubMed: 3746494] 
7. Tilley BC, Johnson CC, Schultz LR, Buffler PA, Joseph CL. Risk of colorectal cancer among automotive pattern and model makers. J Occup Med 1990;32:541-6. [PubMed: 2380803]

8. Garabrant DH, Peters JM, Mack TM, Bernstein L. Job activity and colon cancer risk. Am J Epidemiol 1984;119:1005-14. [PubMed: 6731427]

9. Ehrlich A, Rohl AN, Holstein EC. Asbestos bodies in carcinoma of colon in an insulation worker with asbestosis. JAMA 1985;254:2932-3. [PubMed: 4057514]

10. Fredriksson M, Bengtsson NO, Hardell L, Axelson O. Colon cancer, physical activity, and occupational exposures. A case-control study. Cancer 1989;63:1838-42. [PubMed: 2702592]

11. Neugut AI, Murray TI, Garbowski GC, Treat MR, Forde KA, Waye JD, Fenoglio-Preiser C. Association of asbestos exposure with colorectal adenomatous polyps and cancer. J Natl Cancer Inst 1991;83:1827-8. [PubMed: 1744926]

12. Vineis P, Ciccone G, Magnino A. Asbestos exposure, physical activity and colon cancer: a casecontrol study. Tumori 1993;79:301-3. [PubMed: 8116070]

13. Bertazzi PA, Consonni D, Bachetti S, Rubagotti M, Baccarelli A, Zocchetti C, Pesatori AC. Health effects of dioxin exposure: a 20-year mortality study. Am J Epidemiol 2001;153:1031-44. [PubMed: 11390319]

14. Dement J, Pompeii L, Lipkus IM, Samsa GP. Cancer incidence among union carpenters in New Jersey. J Occup Environ Med 2003;45:1059-67. [PubMed: 14534447]

15. Berlin K, Edling C, Persson B, Ahlborg G, Hillert L, Hogstedt B, Lundberg I, Svensson BG, Thiringer $\mathrm{G}$, Orbaek P. Cancer incidence and mortality of patients with suspected solvent-related disorders. Scand J Work Environ Health 1995;21:362-7. [PubMed: 8571092]

16. Anttila A, Pukkala E, Riala R, Sallmen M, Hemminki K. Cancer incidence among Finnish workers exposed to aromatic hydrocarbons. Int Arch Occup Environ Health 1998;71:187-93. [PubMed: 9591160]

17. Dumas S, Parent ME, Siemiatycki J, Brisson J. Rectal cancer and occupational risk factors: a hypothesis-generating, exposure-based case-control study. Int J Cancer 2000;87:874-9. [PubMed: 10956400]

18. Calvert GM, Ward E, Schnorr TM, Fine LJ. Cancer risks among workers exposed to metalworking fluids: a systematic review. Am J Ind Med 1998;33:282-92. [PubMed: 9481427]

19. Blair A, Zahm SH. Cancer among farmers. Occup Med 1991;6:335-54. [PubMed: 1835166]

20. Forastiere F, Quercia A, Miceli M, Settimi L, Terenzoni B, Rapiti E, Faustini A, Borgia P, Cavariani F, Perucci CA. Cancer among farmers in central Italy. Scand J Work Environ Health 1993;19:3829. [PubMed: 8153589]

21. Zhong Y, Rafnsson V. Cancer incidence among Icelandic pesticide users. Int J Epidemiol 1996;25:1117-24. [PubMed: 9027514]

22. de Jong G, Swaen GM, Slangen JJ. Mortality of workers exposed to dieldrin and aldrin: a retrospective cohort study. Occup Environ Med 1997;54:702-7. [PubMed: 9404316]

23. Swaen GM, de Jong G, Slangen JJ, van Amelsvoort LG. Cancer mortality in workers exposed to dieldrin and aldrin: an update. Toxicol Ind Health 2002;18:63-70. [PubMed: 12868794]

24. Ditraglia D, Brown DP, Namekata T, Iverson N. Mortality study of workers employed at organochlorine pesticide manufacturing plants. Scand J Work Environ Health 1981;7 4:140-6. [PubMed: 7330625]

25. Leet T, Acquavella J, Lynch C, Anne M, Weiss NS, Vaughan T, Checkoway H. Cancer incidence among alachlor manufacturing workers. Am J Ind Med 1996;30:300-6. [PubMed: 8876798]

26. Acquavella JF, Riordan SG, Anne M, Lynch CF, Collins JJ, Ireland BK, Heydens WF. Evaluation of mortality and cancer incidence among alachlor manufacturing workers. Environ Health Perspect 1996;104:728-33. [PubMed: 8841758]

27. Acquavella JF, Delzell E, Cheng H, Lynch CF, Johnson G. Mortality and cancer incidence among alachlor manufacturing workers 1968-99. Occup Environ Med 2004;61:680-5. [PubMed: 15258274]

28. Soliman AS, Smith MA, Cooper SP, Ismail K, Khaled H, Ismail S, McPherson RS, Seifeldin IA, Bondy ML. Serum organochlorine pesticide levels in patients with colorectal cancer in Egypt. Arch Environ Health 1997;52:409-15. [PubMed: 9541361] 
29. Hoar SK, Blair A, Holmes FF, Boysen C, Robel RJ. Herbicides and colon cancer. Lancet 1985;1:1277-8. [PubMed: 2860478]

30. Kaerlev L, Lynge E, Sabroe S, Olsen J. Colon cancer controls versus population controls in casecontrol studies of occupational risk factors. BMC Cancer 2004;4:15. [PubMed: 15102323]

31. Brown DP. Mortality of workers employed at organochlorine pesticide manufacturing plants--an update. Scand J Work Environ Health 1992;18:155-61. [PubMed: 1615289]

32. Amoateng-Adjepong Y, Sathiakumar N, Delzell E, Cole P. Mortality among workers at a pesticide manufacturing plant. J Occup Environ Med 1995;37:471-8. [PubMed: 7670904]

33. MacLennan PA, Delzell E, Sathiakumar N, Myers SL. Mortality among triazine herbicide manufacturing workers. J Toxicol Environ Health A 2003;66:501-17. [PubMed: 12712593]

34. Alavanja MC, Sandler DP, McMaster SB, Zahm SH, McDonnell CJ, Lynch CF, Pennybacker M, Rothman N, Dosemeci M, Bond AE, Blair A. The Agricultural Health Study. Environ Health Perspect 1996;104:362-9. [PubMed: 8732939]

35. Percy, C.; Van Holten, V.; Muir, C. International Classification of Diseases for Oncology. 2nd. Geneva: World Health Organization; 1990.

36. Dosemeci M, Alavanja MC, Rowland AS, Mage D, Zahm SH, Rothman N, Lubin JH, Hoppin JA, Sandler DP, Blair A. A quantitative approach for estimating exposure to pesticides in the Agricultural Health Study. Ann Occup Hyg 2002;46:245-60. [PubMed: 12074034]

37. Breslow, NE.; Day, NE. Statistical methods in cancer research. Vol II. The design and analysis of cohort studies. Lyon: IARC; 1987. p. 82-118.Scientific Publication no.82

38. Tarone RE, Alavanja MC, Zahm SH, Lubin JH, Sandler DP, McMaster SB, Rothman N, Blair A. The Agricultural Health Study: factors affecting completion and return of self-administered questionnaires in a large prospective cohort study of pesticide applicators. Am J Ind Med 1997;31:233-42. [PubMed: 9028440]

39. Kiely, T.; Donaldson, D.; Grube, A. Washington, DC: 2004 [August 28, 2006]. Pesticide industry sales and usage: 2000 and 2001 market estimates, Environmental Protection Agency. http://www.epa.gov/oppbead1/pestsales/01pestsales/market_estimates2001.pdf

40. Smegal, DC. Washington, DC: 2000 [August 28, 2006]. Chlorpyrifos Revised Risk Assessment and Agreement with Registrants. http://www.epa.gov/oppsrrd1/op/chlorpyrifos/hedrra.pdf

41. Waters MD, Simmon VF, Mitchell AD, Jorgenson TA, Valencia R. An overview of short-term tests for the mutagenic and carcinogenic potential of pesticides. J Environ Sci Health B 1980;15:867-906. [PubMed: 7002991]

42. Patnaik KK, Tripathy NK. Farm-grade chlorpyrifos (Durmet) is genotoxic in somatic and germ-line cells of Drosophila. Mutat Res 1992;279:15-20. [PubMed: 1374528]

43. Amer SM, Aly FA. Cytogenetic effects of pesticides. IV. Cytogenetic effects of the insecticides Gardona and Dursban. Mutat Res 1992;279:165-70. [PubMed: 1377331]

44. Sobti RC, Krishan A, Pfaffenberger CD. Cytokinetic and cytogenetic effects of some agricultural chemicals on human lymphoid cells in vitro: organophosphates. Mutat Res 1982;102:89-102. [PubMed: 6981766]

45. Woodruff RC, Phillips JP, Irwin D. Pesticide-induced complete and partial chromosome loss in screens with repair-defective females of Drosophila melanogaster. Environ Mutagen 1983;5:83546. [PubMed: 6418539]

46. Bebe FN, Panemangalore M. Exposure to low doses of endosulfan and chlorpyrifos modifies endogenous antioxidants in tissues of rats. J Environ Sci Health B 2003;38:349-63. [PubMed: 12716052]

47. Waddell BL, Zahm SH, Baris D, Weisenburger DD, Holmes F, Burmeister LF, Cantor KP, Blair A. Agricultural use of organophosphate pesticides and the risk of non-Hodgkin's lymphoma among male farmers (United States). Cancer Causes Control 2001;12:509-17. [PubMed: 11519759]

48. Lee WJ, Colt JS, Heineman EF, McComb R, Weisenburger DD, Lijinsky W, Ward MH. Agricultural pesticide use and risk of glioma in Nebraska, United States. Occup Environ Med 2005;62:786-92. [PubMed: 16234405]

49. Alavanja MC, Dosemeci M, Samanic C, Lubin J, Lynch CR, Knott C, Barker J, Hoppin JA, Sandler DP, Coble J, Thomas K, Blair A. Pesticides and lung cancer risk in the agricultural health study cohort. Am J Epidemiol 2004;160:876-85. [PubMed: 15496540] 
50. Lee WJ, Blair A, Hoppin JA, Lubin JH, Rusiecki JA, Sandler DP, Dosemeci M, Alavanja MC. Cancer incidence among pesticide applicators exposed to chlorpyrifos in the Agricultural Health Study. J Natl Cancer Inst 2004;96:1781-9. [PubMed: 15572760]

51. IARC. Aldicarb. IARC Monogr Eval Carcinog Risks Hum. Lyon, France: International Agency for Research on Cancer; 1991. p. 93-113.

52. Muir K, Rattanamongkolgul S, Smallman-Raynor M, Thomas M, Downer S, Jenkinson C. Breast cancer incidence and its possible spatial association with pesticide application in two counties of England. Public Health 2004;118:513-20. [PubMed: 15351225]

53. Lee WJ, Hoppin JA, Blair A, Lubin JH, Dosemeci M, Sandler DP, Alavanja MC. Cancer Incidence among Pesticide Applicators Exposed to Alachlor in the Agricultural Health Study. Am J Epidemiol 2004;159:373-80. [PubMed: 14769641]

54. Garabrant DH, Philbert MA. Review of 2,4-dichlorophenoxyacetic acid (2,4-D) epidemiology and toxicology. Crit Rev Toxicol 2002;32:233-57. [PubMed: 12184504]

55. Hou L, Lee WJ, Rusiecki J, Hoppin JA, Blair A, Bonner MR, Lubin JH, Samanic C, Sandler DP, Dosemeci M, Alavanja MC. Pendimethalin exposure and cancer incidence among pesticide applicators. Epidemiology 2006;17:302-7. [PubMed: 16452832]

56. Iacopetta B. Are there two sides to colorectal cancer? Int J Cancer 2002;101:403-8. [PubMed: 12216066]

57. Wei EK, Giovannucci E, Wu K, Rosner B, Fuchs CS, Willett WC, Colditz GA. Comparison of risk factors for colon and rectal cancer. Int J Cancer 2004;108:433-42. [PubMed: 14648711]

58. Arbman G, Axelson O, Fredriksson M, Nilsson E, Sjodahl R. Do occupational factors influence the risk of colon and rectal cancer in different ways? Cancer 1993;72:2543-9. [PubMed: 8402474]

59. Brownson RC, Zahm SH, Chang JC, Blair A. Occupational risk of colon cancer. An analysis by anatomic subsite. Am J Epidemiol 1989;130:675-87. [PubMed: 2773916]

60. Blair A, Tarone R, Sandler D, Lynch CF, Rowland A, Wintersteen W, Steen WC, Samanic C, Dosemeci M, Alavanja MC. Reliability of reporting on life-style and agricultural factors by a sample of participants in the Agricultural Health Study from Iowa. Epidemiology 2002;13:94-9. [PubMed: 11805592]

61. Hoppin JA, Yucel F, Dosemeci M, Sandler DP. Accuracy of self-reported pesticide use duration information from licensed pesticide applicators in the Agricultural Health Study. J Expo Anal Environ Epidemiol 2002;12:313-8. [PubMed: 12198579]

62. Coble J, Arbuckle T, Lee W, Alavanja M, Dosemeci M. The validation of a pesticide exposure algorithm using biological monitoring results. J Occup Environ Hyg 2005;2:194-201. [PubMed: 15764542]

63. Savitz DA, Olshan AF. Multiple comparisons and related issues in the interpretation of epidemiologic data. Am J Epidemiol 1995;142:904-8. [PubMed: 7572970]

64. Thompson JR. Invited commentary: Re: "Multiple comparisons and related issues in the interpretation of epidemiologic data". Am J Epidemiol 1998;147:801-6. [PubMed: 9583708]

65. Goodman SN. Multiple comparisons, explained. Am J Epidemiol 1998;147:807-12. [PubMed: 9583709] 


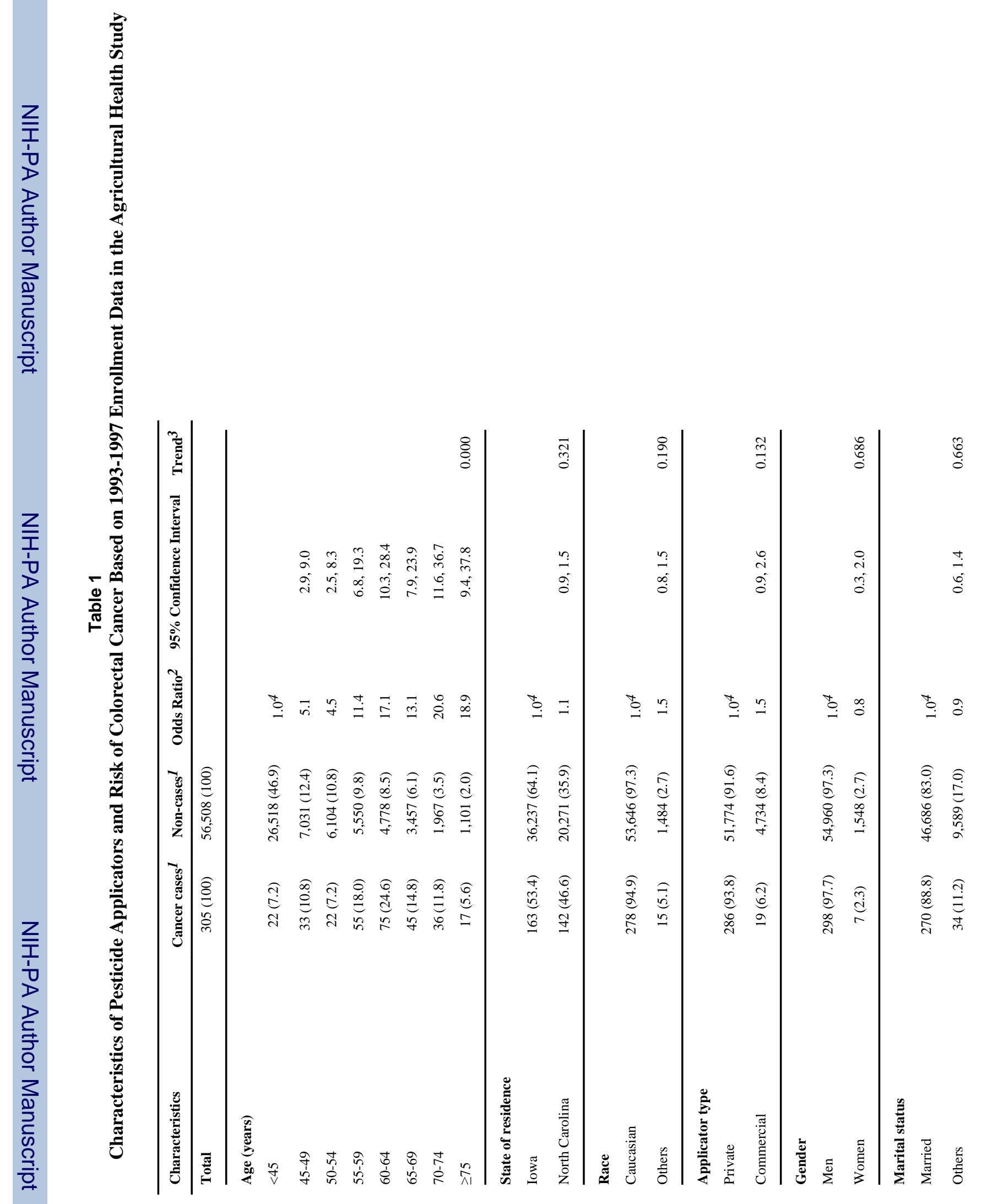




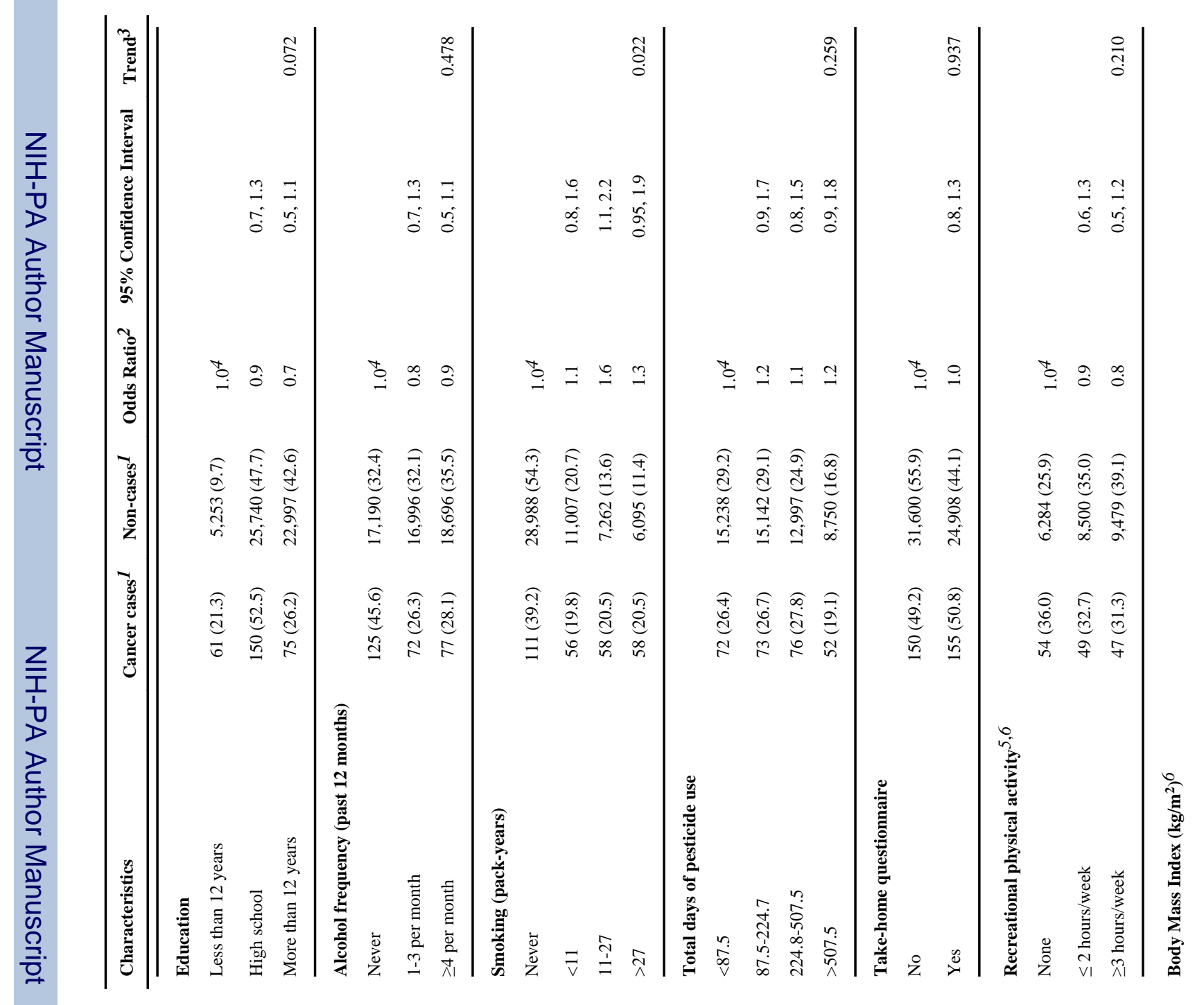

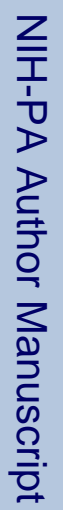




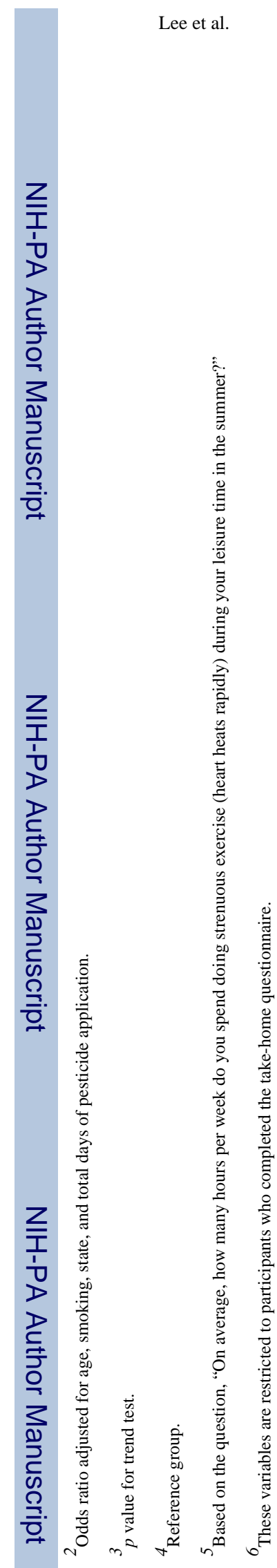

Int J Cancer. Author manuscript; available in PMC 2010 August 27. 


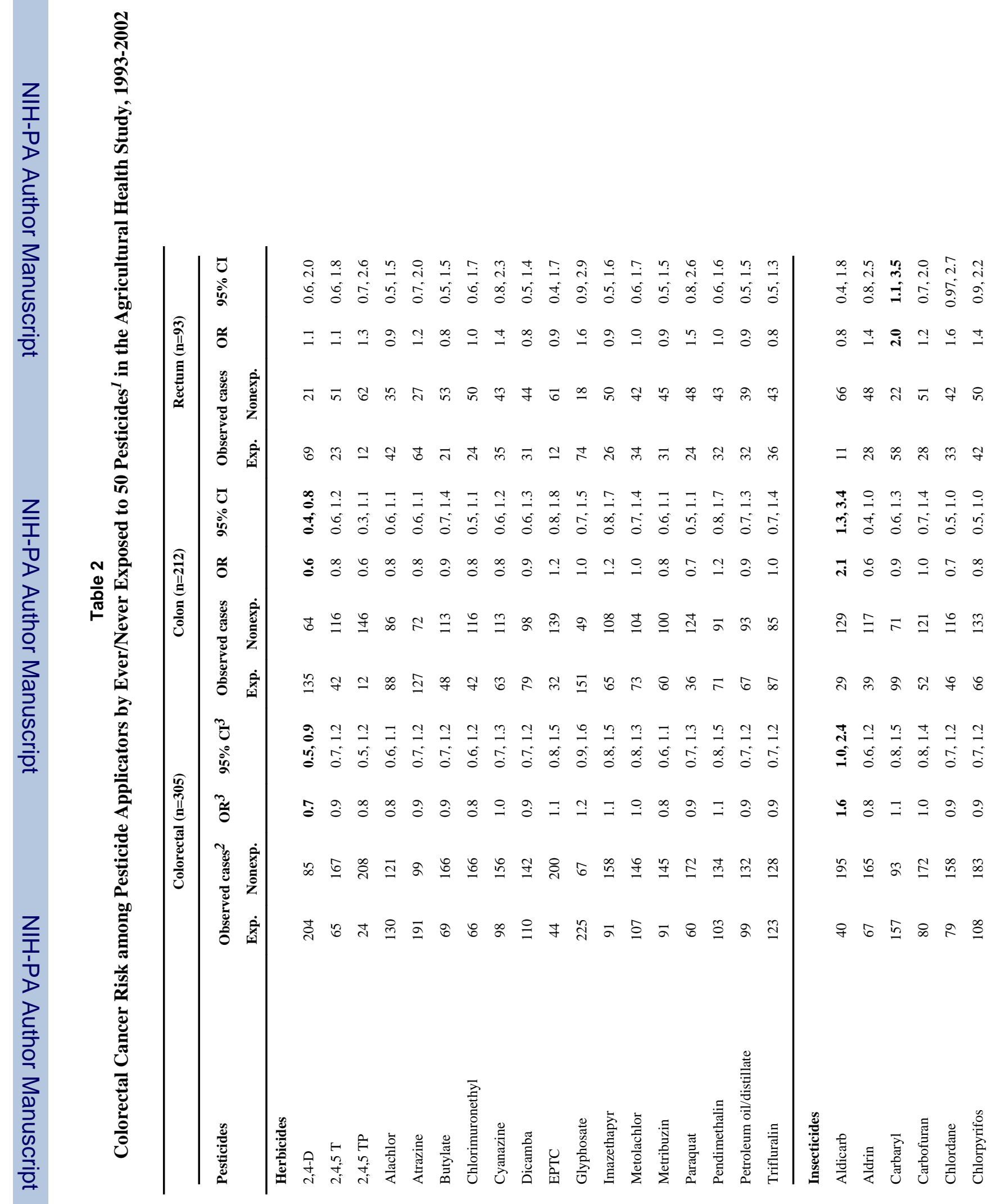

Int J Cancer. Author manuscript; available in PMC 2010 August 27. 


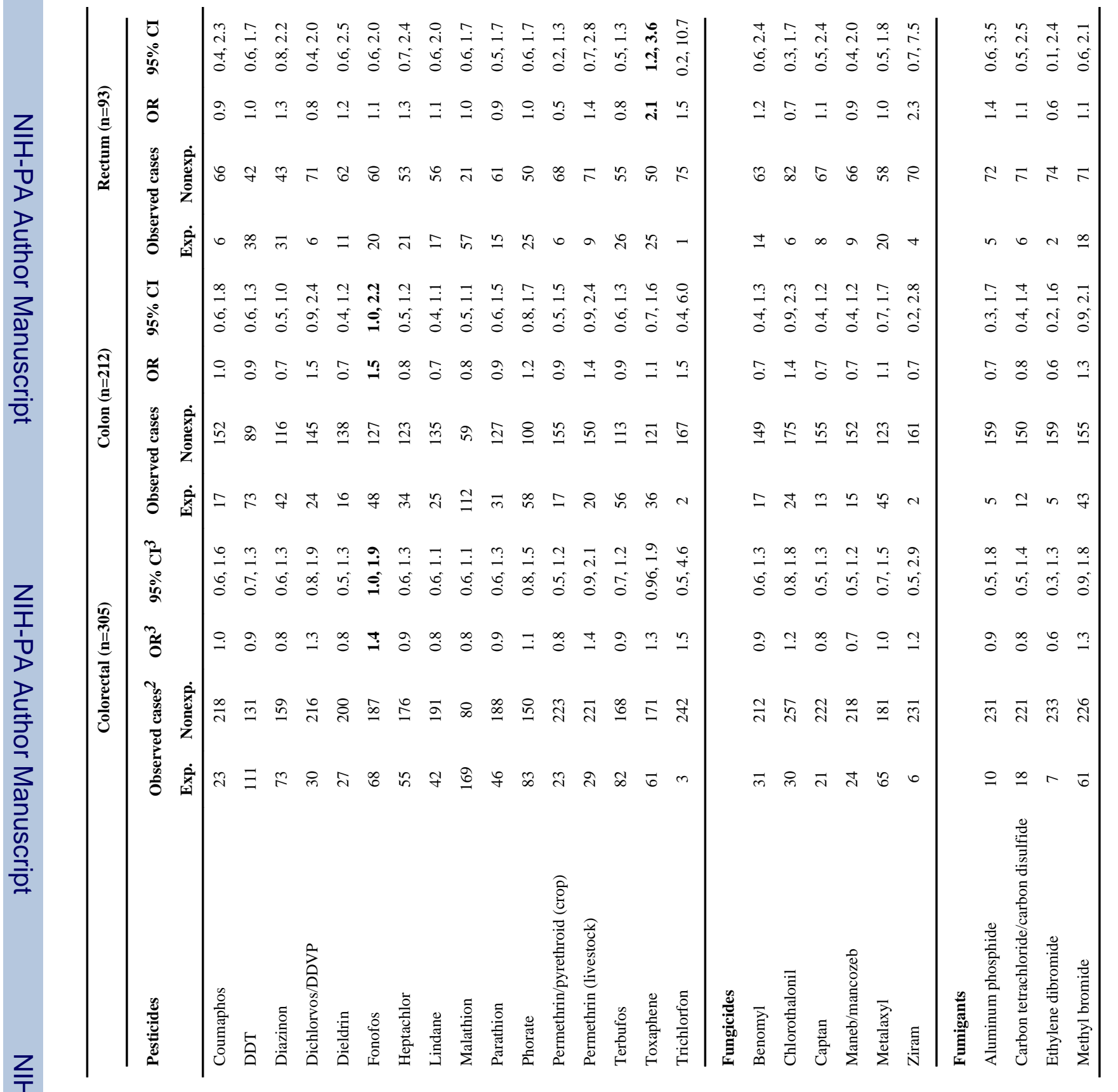




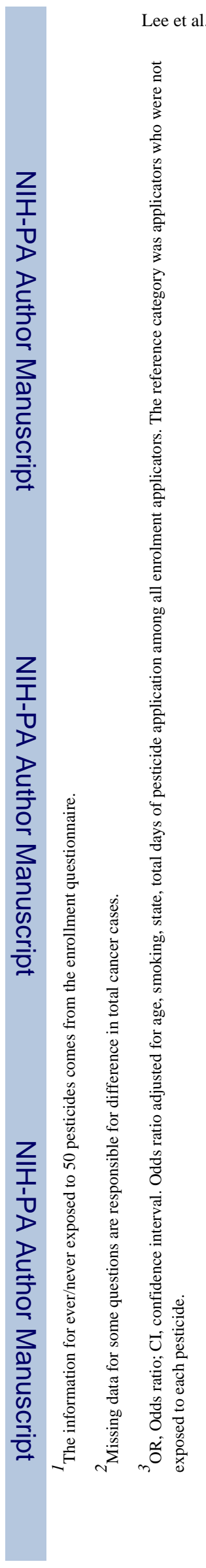

Page 17

Int J Cancer. Author manuscript; available in PMC 2010 August 27. 


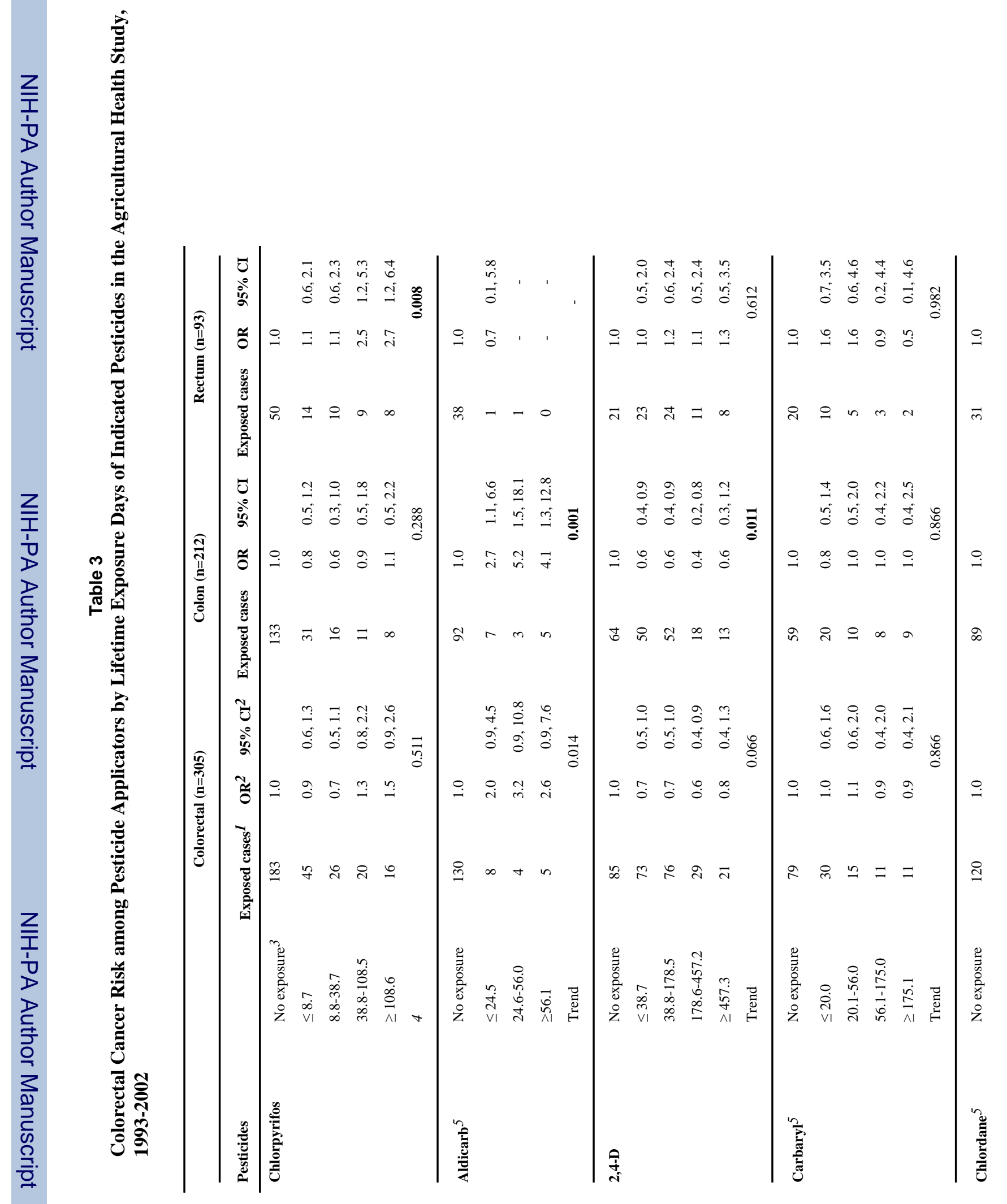




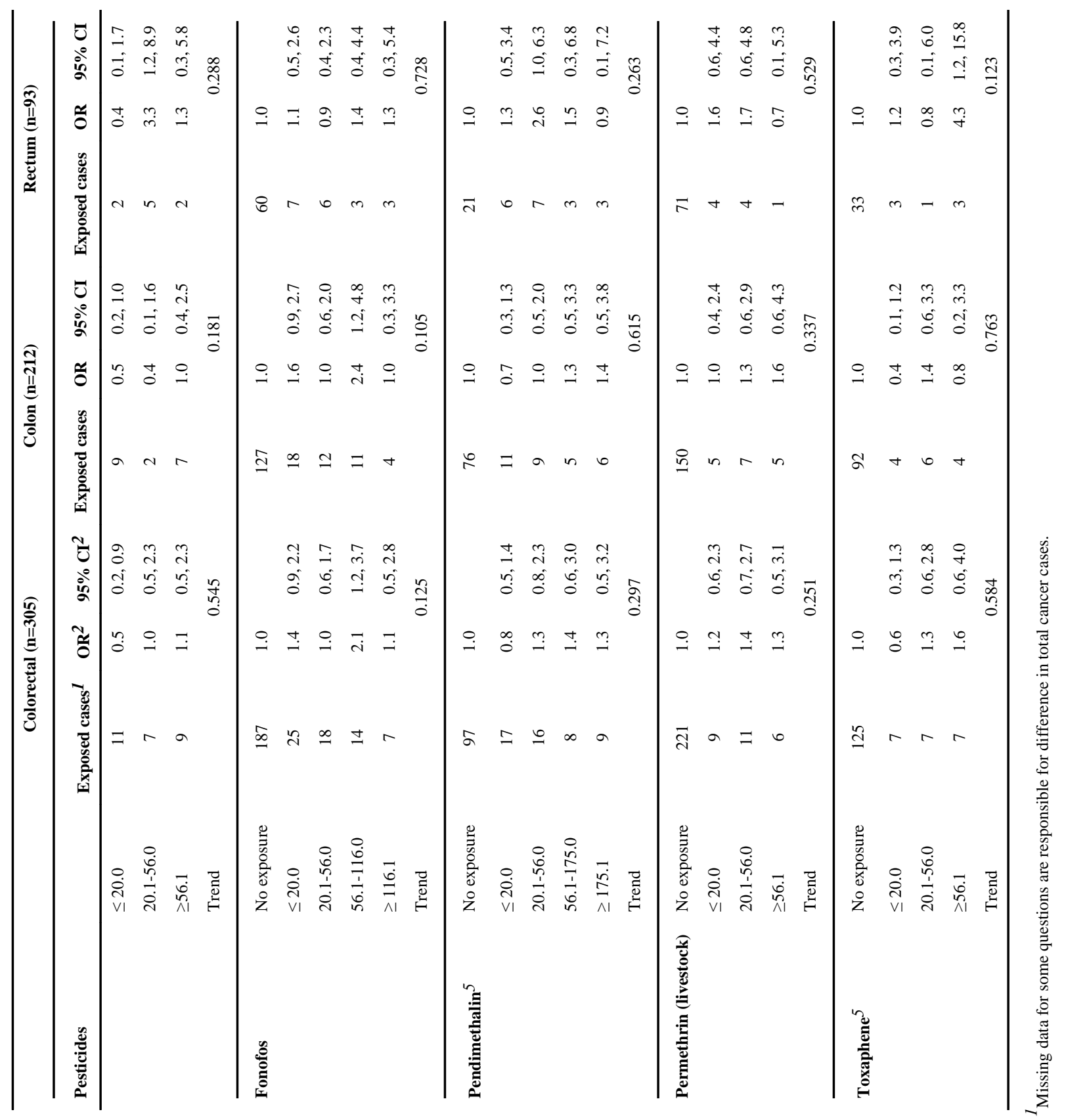




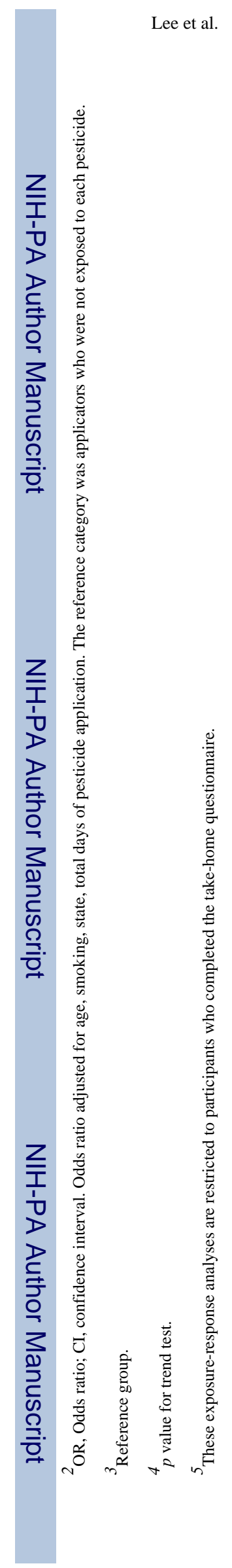

Int J Cancer. Author manuscript; available in PMC 2010 August 27. 